\title{
Revolución de Octubre, historia y memoria ${ }^{*}$
}

\author{
October Revolution, history and memory \\ Carlos Barros \\ Red Académica Internacional Historia a Debate
}

Quiero empezar con una declaración de fe (científica): la historia es objetiva y subjetiva al mismo tiempo, son dos aspectos de la escritura de la historia que no se deberían separar ${ }^{1}$. Hablaré como historiador, pero también como testigo y fuente histórica, no de la Revolución de Octubre (todavía no había nacido) pero si de la huella que dejó a lo largo del siglo $\mathrm{XX}^{2}$. Tuve el gusto y la suerte haber formado parte activa en la Universidad de Madrid (antes de que se llamara Universidad Complutense), en los años 1967-1968, de la última generación histórica de jóvenes universitarios impactados por la Revolución Rusa.

\section{Testimonio}

Es por ello que para preparar esta conferencia decidí dejar primero que fluyeran mis recuerdos de las lecturas de las obras de Lenin de los años 60 y 70, cuando teníamos como actividad extraacadémica vital leer a los fundadores del marxismo y sus sucesores, entre otros libros ilegales. Nos venía bien para nuestro accionar clandestino, porque la España franquista tenía puntos en común con la Rusia zarista, pese a la diferencia cronológica y geopolítica. Militaba en la organización universitaria del Partido Comunista de España, eje impulsor y vertebrador de la oposición democrática, y seguíamos al Partido Bolchevique desarrollando en las aulas y en las fábricas la lucha de masas -que en Rusia derrocó a la autocracia zarista- para tumbar el régimen fascista que el General Franco erigió sobre las cenizas de una guerra civil que ganaron los franquistas con la ayuda militar de Hitler y de Mussolini.

Durante 50 años guardé en la memoria, siempre selectiva, el coraje personal de Vladimir Ilich Uliánov y sus compañeros. Cuenta alguno de sus biógrafos ${ }^{3}$ que cuando

\footnotetext{
* Versión escrita de la conferencia de Carlos Barros en el Coloquio Internacional "La Revolución Socialista Rusa de 1917: reflexiones y perspectivas". Auditorio del Instituto de Investigaciones José María Luis Mora, Ciudad de México, 6 de noviembre de 2017 (https://youtu.be/jdzOM0gDcvU).

${ }^{1}$ Carlos BARROS, Por un nuevo concepto de la historia como ciencia (Quito, 2005) en https://youtu.be/f_41qV42A1I.

${ }^{2}$ Viví en directo a través de mi padre, trabajador de la construcción naval, el influjo de la revolución soviética en los años 30, durante la II República española, hasta su muerte en 1998, Carlos BARROS "Manuel Barros, obra e fonte", estudio introductorio a Manuel BARROS, O rapas da aldea. Memorias dun traballador (19181976), Santiago de Compostela, 2008, pp. 31-33.

${ }^{3}$ No me sería difícil encontrar las referencias textuales, aunque prefiero no empañar la espontaneidad imaginaria y emocional de la remembranza.
} 
volvía de Finlandia ${ }^{4}$ a Petrogrado a través de los hielos, en vísperas de octubre de 1917 , comentó de pie sobre unos hielos que se abrían, la pena que le embargaba tener que morir de manera tan fútil, habiendo tantas cosas que hacer... Lenin y los dirigentes bolcheviques atribuían un colosal sentido de la historia a lo que hacían. Se dijo después que la Revolución Rusa cambió la historia, pero ellos de alguna forma ya lo sabían en 1917. Otro recuerdo parecido es la conversación de Lenin y Trotski en los pasillos del Smolny, cuando ya habían tomado el poder. No podían dormir comentando, tumbados en el suelo, que los podían matar si fracasaban. Estaban dispuestos a arriesgarlo todo: lucidez revolucionaria que impresionó a un estudiante veinteañero a finales de los años 60. Las influencias de aquellas lecturas clandestinas eran intelectuales y políticas, también éticas y épicas, tocadas de romanticismo revolucionario.

La verdad es que tuve, en aquellos años, dudas iniciales sobre Lenin y la Revolución de Octubre. Mi abuelo y mi padre eran comunistas y por parte de mi madre, trabajadora del sector metal-gráfico, entronco con los orígenes del Partido Socialista en Vigo (Galicia). Tenía mis dudas de primerizo sobre la postura de Lenin y los bolcheviques hacia la democracia. En España estábamos luchando contra una dictadura que queríamos sustituir por un régimen democrático y socialista. Por este orden, la reivindicación de la democracia siempre por delante. Vivíamos bajo un Régimen tremendamente represivo con quienes pensaban diferente y nos parecía contradictorio tener como objetivo instaurar, en su lugar, la "dictadura del proletariado". Sabía que se trataba de un concepto sociológico relativo a la clase social que gobierna, o quiere gobernar, pero a esas alturas del siglo éramos conocedores que la "dictadura", en nombre del proletariado, podía llegar a ser una dictadura de verdad, incluso para sus propios fundadores y partidarios. Me costó entenderlo, pero pudo más la urgencia de la lucha antifranquista. Pocos años después el PCE se declaró partidario de un "socialismo en libertad".

Igualmente, se me hizo complicado asumir la cuestión de la violencia en la obra de Lenin. En 1968 habían pasado ya veinte años desde que el Partido Comunista de España abandonara la lucha guerrillera y se planteara una lucha pacífica, siguiendo precisamente las orientaciones leninistas de la época zarista, para organizar y movilizar los trabajadores, entrando en los sindicatos verticales del Régimen. Reemplazando, en consecuencia, la insurrección armada por una huelga general política y una huelga nacional para echar abajo la dictadura de Franco. Tampoco teníamos otra opción, aun así, no fue fácil: el bando vencedor de la guerra civil había hecho desaparecer a más de 130.000 españoles de izquierda, republicanos y nacionalistas, y el miedo era palpable. Tuvo que nacer una nueva generación de obreros y estudiantes que, treinta años después de la gran represión, le plantó cara a la dictadura. Tan dura experiencia nos hizo poner en práctica, en los años 60 y 70, de manera rectificada en relación a los temas de democracia y violencia, las enseñanzas de la Revolución de Octubre, en un contexto y época muy diferentes, siguiendo, así y todo, la metodología intelectual del fundador de la Unión Soviética que solía basar sus posiciones

\footnotetext{
${ }^{4}$ En cuyos bosques se escondiera de la policía de Kérenski, después de las jornadas de Julio, aprovechó para escribir El Estado y la revolución.
} 
en el principio de realidad, añadiendo nosotros la necesidad épico-ética de cierta coherencia entre los fines y los medios.

Me resultó por consiguiente útil, como dirigente del partido en la clandestinidad, la lectura interactiva de Lenin, sobre todo ese sentido que tenía de la objetividad de los hechos $^{5}$. Repetía, en sus escritos de combate, que "la teoría es gris y el árbol de la vida verde eternamente" o "la vida tendrá la última palabra". Pensaba sin duda que la frase era suya, ya de mayor y con una cultura más general (era estudiante de Ingeniería Superior en los años de Madrid), supe que se trataba de un aforismo del poeta y científico romántico alemán Johann Wolfgang von Goethe (1749-1832). Lenin situaba la realidad y la práctica por delante de la ideología y la teoría, se mostraba de ese modo opuesto a cualquier tipo de doctrinarismo como marxista y como dirigente político, dijeran lo que dijesen sus adversarios dentro y fuera de la II Internacional, y sus epígonos después. Influencia racionalista del jefe de los bolcheviques que completaba la recibida, en 1968, por nuestra generación por la vía emocional e imaginaria. Lenin y los dirigentes bolcheviques compaginaban de manera espléndida el trabajo teórico (principalmente en la clandestinidad, el exilio o el destierro) con la militancia política y social, sabedores de que lo primero se nutre de lo segundo, y viceversa ${ }^{6}$.

Lenin, hijo de un pequeño terrateniente, había recibido una formación clásica, era de los pocos privilegiados que pudieron ir a la universidad ${ }^{7}$ en la Rusia de los zares: un país enorme de más de 120 millones de habitantes con sólo un reducido número de estudiantes universitarios. Tenía un origen social semejante, pues, a los dirigentes más creativos del marxismo desde los fundadores Marx y Engels hasta Antonio Gramsci, pasando por Rosa Luxemburgo y tantos otros. Una elite intelectual que, entre finales del siglo XIX y principios del siglo XX, jugó un papel esencial en la organización de las I ${ }^{8}$, II y III Internacionales de los trabajadores, volviendo ciertamente del revés las enseñanzas académicas provechosamente recibidas. La transmisión cultural de este marxismo, y del compromiso social de los intelectuales, sigue, cuando menos hasta los años 60 y 70 del pasado siglo, una vía académica intergeneracional, paralela a la vía política y social, más condicionada por el contexto que por los libros ${ }^{9}$.

Hablaremos ahora menos de memoria y más de la historia concreta de la Revolución de Octubre en su primer centenario. Dividiremos el proceso revolucionario ruso

\footnotetext{
${ }^{5}$ Por el contrario, sus detractores lo tenían por voluntarista, pero jamás hubiera triunfado sin ese fino olfato para captar con anticipación el movimiento de lo real.

${ }^{6}$ Naturalmente la teoría orienta la práctica, pero menos de lo que se piensa, al menos cuando la ideología se está formando o su formulación permanece abierta: el caso del marxismo militante hasta los años 30.

7 Estudió derecho, y empezó su compromiso, como otros universitarios de izquierda, dando clases a los obreros, además de participar en la lucha anti-zarista.

${ }^{8}$ Marx compartió en la I Internacional protagonismo y rivalidad con el anarquista Bakunin, ruso descendiente de un gran terrateniente y filósofo universitario de formación, a diferencia del francés Proudhon, un trabajador autodidacta devenido filosofo anarquista.

${ }^{9}$ La transformación en España, en la segunda década del siglo XXI, del movimiento indignado del 15M en el partido Podemos fue asimismo posible gracias al grupo fundacional de jóvenes profesores de la Universidad Complutense de Madrid imbuidos de marxismo gramsciano, junto con otras influencias como el "socialismo del siglo XXI" y, ante todo, la realidad de un movimiento social y global de nuevo tipo.
} 
y su influencia, que marcó de manera indeleble la historia del siglo XX, en tres tiempos: 1917, el pequeño siglo XX y el nuevo siglo XXI. Dando por supuesto más importancia a los verdes hechos de la realidad que a una ideología que, pasada su edad dorada, se petrificó con Stalin, a diferencia del llamado "marxismo occidental" académicamente lúcido pero despegado -salvo excepciones- de los movimientos sociales y la práctica política.

\section{7}

Analizaremos el acontecimiento-fundador de 1917 en tres dimensiones: contexto, coyuntura y acción subjetiva. El contexto extraordinario que posibilitó la Revolución bolchevique fue, como es sabido, la Gran Guerra que el Zar impuso a su pueblo desencadenando una pavorosa crisis social en una Rusia semi-feudal ${ }^{10}$. El conflicto bélico indujo una inflación y un desempleo galopantes, salarios inmundos y jornadas extenuantes para los trabajadores, hambrunas y una enorme cantidad de fallecidos: dos millones de rusos murieron durante la I Guerra Mundial. Se desataron fortísimos movimientos sociales antizaristas, dirigidos por los obreros que ya habían protagonizado doce años antes la Revolución de 1905. En 1917, estalla en Petrogrado ${ }^{11}$ la Revolución de Febrero, secundada por el resto de la Rusia urbana y parte del Ejercito, que derrocan para siempre la autocracia de los zares, Se formó un gobierno de influencia menchevique ${ }^{12}$, que decide continuar la guerra a pesar del mandato recibido durante la Revolución de Febrero. Se sucede una segunda ola de grandes manifestaciones. Lenin y otros revolucionarios se sirven de un tren alemán ${ }^{13}$ para regresar a Rusia. Llegó a la estación de Finlandia de Petrogrado, y allí Lenin proclamó subido a un tanque las Tesis de Abril, clamando que, en lugar de seguir apoyando al gobierno menchevique de Kérenski, el traidor que había mantenido a Rusia en la guerra, había que luchar ahora por "Todo el poder para los Soviets", que se habían extendido desde Petrogrado a las ciudades de todas las Rusias y sus frentes militares ${ }^{14}$.

El 25 de octubre en el calendario ortodoxo ( 7 de noviembre en el calendario occidental) tendrá lugar lo que será el momento más simbólico de la Revolución de Octubre

\footnotetext{
${ }^{10}$ Paradójicamente el último Zar, Nicolás II, había desarrollado la gran industria en las ciudades, creando un proletariado que resultó muy combativo: lo derrocó en 1917 y lo ajustició en 1918 para evitar que los Romanov cayesen en manos del Ejército Blanco.

${ }^{11}$ En Petrogrado se había constituido el primer Soviet obrero (consejo asambleario) en 1905, la gran ciudad industrial se llamó después Leningrado y a partir del retorno en 1991 de la Unión Soviética al capitalismo, recobró el nombre zarista de San Petersburgo, que fuera desde 1721 capital del Imperio ruso.

${ }^{12}$ El Partido Obrero Socialdemócrata Ruso se había dividido, en 1903, entre una mayoría de izquierda o 'bolchevique' ("miembro de la mayoría" en ruso) y una minoría más conservadora o 'menchevique' ("miembro de la minoría" en ruso).

13 Alemania estaba muy interesada en que Rusia, aliada con su archienemiga Francia, abandonara la guerra y facilitó que los subversivos rusos contrarios a la guerra volvieran del exilio: Lenin sentía que no podía desaprovechar la ansiada oportunidad de vivir en primera persona el proceso revolucionario.

${ }^{14}$ La cúpula intelectual de Petrogrado de los Soviets campesinos no apoyaron en Octubre a los Soviets de obreros y soldados (en su mayoría campesinos).
} 
que solemos celebrar el 7 de noviembre: el asalto exitoso al Palacio de Invierno ${ }^{15}$, sede del Gobierno menchevique, bajo la bandera del "pan (contra el hambre), paz (salir de la Gran Guerra) y tierra (reparto de los grandes latifundios entre los pequeños campesinos rusos)". El mismo Lenin redactó a primera hora el breve texto fundacional del poder soviético:

¡A los ciudadanos de Rusia! El Gobierno Provisional ha sido depuesto. El Poder del Estado ha pasado a manos del Comité Militar Revolucionario que es un órgano del Soviet de diputados obreros y soldados de Petrogrado y se encuentra al frente del proletariado y la guarnición de la capital. Los objetivos por los que ha luchado el pueblo (la propuesta inmediata de una paz democrática, la supresión de la propiedad agraria de los terratenientes, el control obrero de la producción y la constitución de un Gobierno Soviético) están asegurados. ¡Viva la Revolución de los obreros, soldados y campesinos! El Comité Militar Revolucionario del Soviet de Diputados Obreros y Soldados de Petrogrado. 25 de octubre de 1917,10 de la mañana ${ }^{16}$.

La toma del poder por parte de los obreros, soldados y marinos pro-bolcheviques de la capital industrial de Rusia fue ratificada de inmediato por el II Congreso de los Soviets de toda Rusia que había sido convocado justamente en Petrogrado para los días 25-27 de octubre de 1917. Paradojalmente fue una insurrección armada más bien pacífica, prácticamente sin bajas, otra cosa será la guerra civil posterior. Perdido el apoyo del Ejército y de la Marina en manos de los soldados y marinos organizados en soviets revolucionarios, el Gobierno de Kérenski cae como una fruta madura. En la Revolución de Octubre en Petrogrado participaron obreros de la Guardia Roja, soldados de la guarnición de Petrogrado y marinos de Kronstadt y Finlandia en cantidad de miles, no grandes masas.

La rápida y fácil victoria de los militares y obreros dirigidos por el POSDR bolchevique, replicada en Moscú y en gran parte de Rusia, fue posible gracias a una especial y compleja coyuntura de guerra, crisis social y crisis política (el Gobierno Provisional de Kérenski mandaba poco): entre golpes y contragolpes, los insurgentes ocuparon simplemente el vacío de poder existente. Fue decisivo, sin lugar a duda, el genio sensible de Lenin para entender la confusa coyuntura política y, sobre todo, el estado de ánimo de las masas. Y desde el punto de vista organizativo el talento de Trotski, Presidente del Soviet de Petrogrado, Presidente del Comité Militar Revolucionario y posteriormente creador del Ejército Rojo que ganará la guerra civil contra la contrarrevolución blanca.

Historiográficamente nos encontramos aquí con la cuestión del papel de las individualidades en la historia. Curiosamente, Hobsbawm no valora tanto o nada el papel de Lenin en la Revolución de $1917^{17}$, considera que fue “el ejemplo más impresionante de

15 Ofrecieron escasa resistencia, los soldados y marinos asaltantes tuvieron cinco bajas y los defensores ninguna, William H. CHAMBERLIN, The Russian revolution, 1917-1918: from the overthrow of the czar to the assumption of power by the bolsheviks, 1976, Nueva York, p. 511.

${ }_{17} \mathrm{https} / / / \mathrm{www}$.marxists.org/espanol/lenin/obras/1910s/25-X-1917.htm.

17 Sin embargo, Lenin no tuvo fácil convencer, a su vuelta de los hielos de Finlandia, al Comité Central del POSDR (b) de que había llegado el momento de la toma por las armas del poder para los soviets, como se puede ver en las Actas publicadas en español, por vez primera, en 1967; tuve el gusto de leerlas en la 
toda la historia" de las "revoluciones de masas", suerte de "fenómenos naturales... en gran medida incontrolables", de forma que "los objetivos de Lenin... no venían al caso". Concluyendo que "durante sus primeros diez años su destino lo determinaron las masas rusas, lo que las masas querían o no estaban dispuestas a tolerar. El estalinismo puso fin a

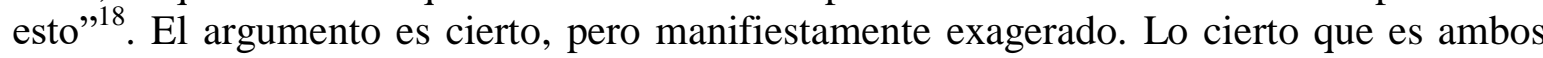
factores son claves, siendo el papel de Lenin y del partido bolchevique más decisivo en la corta duración, que exige decisiones rápidas en horas, días o semanas, y el de los movimientos sociales (obrero, militar y campesino) más importante en la media y larga duración a la hora de secundar o sostener, impulsar u oponerse a los planes de los dirigentes: más allá de la coyuntura y la táctica el sujeto social siempre hace la historia ${ }^{19}$. La cuestión es que el historiador no puede prescindir, en rigor, de la corta duración y las mentalidades, las vanguardias y las individualidades., si quiere escribir una historia completa.

Realmente en Octubre lo que hubo fue una revolución democrática radical en torno a la reivindicación del "pan, paz y tierra" que deseaban los pueblos, guiada por un partido marxista revolucionario que asumió el poder en nombre de una clase obrera que era en aquel entonces una corta minoría -el $6 \%$ de la población- en la Rusia de los zares ${ }^{20}$. De todas maneras, el pequeño pero concentrado proletariado ruso supo aprovechar bien, desde Petrogrado, Moscú y otras ciudades, el lugar de Rusia como el eslabón débil del sistema imperialista segmentado por la guerra.

Es menos conocido el rol de las mujeres en la Revolución Rusa, decía Lenin: "sin ellas no habríamos triunfado" ${ }^{21}$. Tan sencillo como esto: constituían el $47 \%$ de la clase obrera de Petrogrado ${ }^{22}$, los hombres estaban en la guerra y las obreras participaron tanto en las manifestaciones, como en la Guardia Roja y los Soviets, en todo. Otro aspecto reseñable, también minusvalorado, es el derecho de autodeterminación de los pueblos, de actualidad en la España de 2017 con el tema de Cataluña, y hace no hace mucho en Quebec (Canadá) y Escocia (Inglaterra). La Sociedad de Naciones lo reconocía en determinadas circunstancias, y Lenin y el partido bolchevique lo aplicaron de manera taxativa. Se dio la opción a las diferentes naciones y nacionalidades del imperio zarista de separarse de Rusia por medio de un referéndum legal: lo aprovecharon Finlandia en 1917 y Polonia, Estonia,

Universidad de Madrid por recomendación de nuestra llorada Pilar Bravo Castells, responsable de la organización universitaria del PCE.

${ }^{18}$ Eric HOBSBAWM, “¿Podemos escribir la historia de la revolución rusa?, Sobre la historia, 2016, pp. 249250.

${ }^{19}$ Cuando el protagonismo histórico se desplaza al nuevo Estado proclamado socialista, los movimientos sociales desaparecen y el sujeto social sólo retornará seis décadas después una vez agotado el sistema estalinista, merced a la reforma de Gorbachov y la contagiosa influencia de la Caída del Muro en Alemania.

${ }^{20}$ Después del triunfo de la Revolución, en los años 30, tuvo lugar una industrialización acelerada que engendró un proletariado numeroso en la URSS, si bien ya no intervenía en la historia de manera autónoma y directa.

${ }^{21}$ Clara ZETKIN, Recuerdos de Lenin [1924), Barcelona, 1975, p. 49 (file:///C:/Users/Carlos/Google\%20Drive\%20New/Documents/recuerdos-sobre-lenin.pdf).

${ }^{22}$ Las mujeres en la Revolución Rusa, Biblioteca Virtual Omegalfa, 2017, p. 3 (file:///C:/Users/Carlos/Google\%20Drive\%20New/Documents/las-mujeres-en-la-revolucion-rusa.pdf). 
Letonia y Lituania en $1919^{23}$. La mayoría de ellas decidieron, sin embargo, constituir la Federación Soviética de las Naciones Rusas que, desde 1922 hasta 1991, dio lugar a la Unión de Repúblicas Socialistas Soviéticas.

La Revolución tuvo que progresar presto en un contexto de guerra civil con intervención extrajera. A menudo se olvida que las decisiones que Lenin y el partido bolchevique $^{24}$ debieron tomar, entre 1917 y 1923, estuvieron condicionadas por el objetivo prioritario de ganar la guerra contra el Ejército Blanco, organizado por la derecha zarista y apoyado por decenas de miles de soldados de Gran Bretaña, Estados Unidos, Francia y Japón, y otros Estados del viejo Régimen, que llegaron a ocupar una gran parte de territorio ruso $^{25}$. Durante la guerra civil los bolcheviques disolvieron la Asamblea Constituyente (1918), formada en su mayoría por adversarios de la Revolución de Octubre ${ }^{26}$. No obstante, Troski utilizó a oficiales zaristas para formar el Ejército Rojo y en 1921 se estableció, casi terminada la guerra civil y con un país en ruinas, la Nueva Política Económica (NEP) para fortalecer la alianza obrera-campesina a fin de consolidar el hecho de que una gran parte del Ejército zarista engrosara con sus soldados-campesinos la revolución proletaria, lo que hizo posible la victoria en la guerra civil. La NEP dejaba atrás el "comunismo de guerra" e implicó cierta recuperación económica gracias a la vuelta -transitoria- a la economía de mercado en el campo, la reconstrucción de la pequeña y mediana empresa, las facilidades a la inversión extranjera y el acuerdo del Gobierno de Lenin con los empresarios de la época zarista para sacar del caos a la economía rusa, causado por la Gran Guerra, la Guerra Civil y la dura intervención militar extranjera. La NEP duró hasta $1928^{27}$, impulsada primero por Lenin y después por Bujarin, hasta el cambio radical de política promovido por Stalin: planificación quinquenal, nacionalización de la propiedad privada y colectivización forzosa de los campesinos.

Hay una valoración unánime de que el giro ruso de 1917 implica una nueva etapa de la historia mundial. Eric J. Hobsbawm llamó el "Pequeño Siglo XX" a lo que va desde 1917 a 1991, año de la desaparición de la Unión Soviética. Era la primera vez en la historia que una revolución obrera y popular triunfaba: la noticia se propagó por el mundo, entre

\footnotetext{
${ }^{23}$ Maurício CASTRO, “A revoluçom bolchevique e a questom nacional”, Bolcheviques 1917-2017, Teresa MOURE coord., Santiago de Compostela, p. 16.

24 Desde marzo de 1918 el PODSR (bolchevique) fue rebautizado como Partido Comunista de Rusia (bolchevique), en 1925 se convirtió en el Partido Comunista de toda la Unión (bolchevique), y en 1952 en el Partido Comunista de la Unión Soviética (PCUS), perdiendo en el camino el halo revolucionario del término 'bolchevique'.

${ }^{25}$ Nichlas V. RIASANOVSKY, Mark D. STEINBERG, A History of Russia, Oxford University Press, 2005.

${ }^{26}$ Ciertamente se ha de comprender, pero no justificar, hoy sería inconcebible la disolución de un parlamento democráticamente elegido; el propio Lenin se preguntaba "libertad para qué", desvalorización de la democracia representativa como "burguesa" que parte de la "Crítica del Programa del Gotha" (1875) de Carlos Marx, véase Carlos BARROS, "Historia inmediata: marxismo, democracia y socialismo del siglo XXI (problemas y debates)", Fuentes. Revista de la Biblioteca y Archivo Histórico de la Asamblea Legislativa Plurinacional, La Paz (Bolivia), año 10, vol. 5, n 13, abril 2011, pp. 36-44 (http://cbarros.com/spanish/articulos/mentalidades/hi_socialismo.htm).

${ }^{27}$ Hoy 80 años después la cohabitación en la NEP entre lo privado y lo público es parte de la identidad de las experiencias del "socialismo del siglo XXI".
} 
otras vías, a través del libro-testimonio (una suerte de Historia Inmediata) del periodista y comunista norteamericano John Reed, Diez días que estremecieron al mundo (1919). Impacto universal que como ya comentamos afectó a varias generaciones del siglo XX, y sigue estando históricamente vigente en el sentido del "sí, se puede", como decían los millenials indignados siguiendo el lema de la campaña electoral del Barack Obama de 2008 "Yes we can". Ciertamente la principal lección, hoy, de Octubre es que "Sí, se puede" derrocar una clase dirigente corrupta e ineficaz que ha perdido consenso moral entre la población. Pero la voluntad no basta, el contexto es otro, la democracia está implantada irreversiblemente, esperemos- y ya no hay guerras inter-imperialistas porque ya no existen Imperios, todos los Estados están dominados por el mercado global, que engendra movimientos sociales críticos todavía lejos de ser capaces de cambiar el mundo ${ }^{28}$.

La Revolución Rusa, y su desarrollo, recibió coetáneamente críticas importantes de parte de otros marxistas revolucionarios, rusos y no rusos. Rosa Luxemburgo escribió desde la cárcel, en $1918^{29}$, el artículo "La revolución rusa" que no se publicó hasta $1922^{30}$, después de presiones y vacilaciones varias. Reconocía que los bolcheviques rusos "han salvado el honor del proletariado internacional", pero criticaba la disolución de la Asamblea Constituyente, la reforma agraria que crearía pequeños campesinado que -decíano nos iban a ayudar a construir el socialismo, la Paz de Brest Litovsk (en 1918, quedó abolida con el Tratado de Versalles de 1919) por la que los rusos "cedían" a Alemania, Finlandia, Polonia, Estonia, Lituania y Ucrania, a fin de salir de la Gran Guerra como habían prometido en Octubre. La mayor parte del territorio perdido fue recuperado por la Rusia soviética después del fin de la I Guerra Mundial, que se saldó con la derrota de Alemania. Objetivamente la Revolución Rusa no habría triunfado si los bolcheviques no hubieran hecho esas concesiones, paralelamente al repliegue que supuso la Nueva Política Económica $^{31}$ : la práctica (verde) siempre por encima de la teoría (gris).

Siguiendo con las (auto) críticas. El propio Lenin en su "testamento" (notas dictadas a su secretaria), posterior al ictus que sufrió en el año 1922 (murió dos años después), pide que se desplazara a Stalin de la Secretaría General del Comité Central del Partido Comunista de la Unión Soviética, por causa sus cualidades bruscas y autoritarias ${ }^{32}$.

Será Trotski a continuación quien, enfrentado con Stalin, criticará acerbamente el abandono de la democracia directa, la burocratización del nuevo Régimen y su renuncia a la "revolución permanente",33.

${ }^{28}$ Los fines de la historia en el siglo XXI en http://cbarros.com/fines-de-la-historia-en-el-siglo-xxi/.

${ }^{29}$ Meses después, el 15 de enero de 1919, es asesinada por los paramilitares de la ultraderecha, fuerza de choque del Gobierno del socialdemócrata Friedrich Ebert, en el marco de la represión que siguió al fracaso de la revolución espartaquista.

${ }^{30}$ Rosa LUXEMBURGO, La revolución rusa, Madrid, 2017.

31 Otro momento en que Lenin fue decisivo en un cambio de orientación que salvó a la Revolución sin necesidad de imponer un régimen carcelario, como hará después Stalin.

32 Jamás se difundió públicamente en la Unión Soviética, pese a la insistencia de la viuda de Lenin, Nadia Krúpskaya: la evolución posterior de Stalin confirmó en demasía los temores de Lenin (https://www.marxists.org/espanol/lenin/obras/1920s/testamento.htm).

${ }^{33}$ León TROSKI, La revolución traicionada [1936], Madrid, 2001

(http://www.fundacionfedericoengels.net/images/PDF/La\%20revolucion\%20traicionada.pdf). 
Antonio Gramsci, cofundador con Antonio Bordiga del Partido Comunista Italiano e intelectual prominente, encerrado por Mussolini en la cárcel en 1926 (una vez ilegalizado el PCI) hasta su muerte en 1937, escribirá el 24 de noviembre de 1917, en caliente, un artículo sobre la Revolución de Octubre que publicó en $A v a n t i{ }^{34}$ : "La revolución contra el Capital”35. Donde recuerda que, según los fundadores del marxismo, la revolución sólo será factible en los países más desarrollados económicamente, haciendo notar que los bolcheviques buscaron un atajo saltándose la fase capitalista y burguesa en la historia de Rusia. Señaló la paradoja, saludando y justificando en todo caso la audacia del partido de Lenin, ante la miseria de la guerra, la carestía y la carnicería de la guerra, poniendo su confianza en el éxito de la Revolución bolchevique para quemar etapas en Rusia (y conectar con la esperada revolución internacional, añadimos nosotros). En 1926, el PCI y Gramsci se definen tácticamente en favor de Stalin contra Trotski, pero exigen: "queremos estar seguros de que la mayoría del C.C. de la URSS no se propone aplastarles en la lucha y está dispuesta a evitar medidas extremas"36. No fue así. En seguida vino para nuestro egregio prisionero el aislamiento carcelario, el resquemor con Togliatti y el PCUS por olvidarse de su penosa situación y la escritura de los Cuadernos de la Cárcel (1929$1935)^{37}$. Donde desarrolla un concepto de 'hegemonía' contradictorio con la "dictadura del proletariado", planteando la lucha por el poder como una cuestión de fuerza y... consenso, lo que inspiró a finales de los años 70 el movimiento eurocomunista del PCI de Enrico Berlinguer y el PCE de Santiago Carrillo en pro de un "socialismo en libertad"38, pensado para unas sociedades occidentales donde, a diferencia de la Rusia zarista, la clase obrera era sociológicamente mayoritaria y existía una democracia representativa fruto, en gran medida, de la lucha obrera y el sacrificio de los comunistas ${ }^{39}$.

La derrota en Alemania de la revolución espartaquista ${ }^{40}$ en 1919 supuso una enorme decepción entre los bolcheviques, cuyos dirigentes siempre pensaron que la toma del poder en Rusia no sería más que un anticipo de la revolución mundial en los países capitalistas más desarrollados. Tuvieron que teorizar apresuradamente, a la defensiva, la noción de un "socialismo en un solo país" perfilada por Nicolái Bujarin. Iósif Stalin, prácticamente sólo

\footnotetext{
${ }^{34}$ Avanti era el órgano oficial del Partido Socialista Italiano, del que se escindirá Gramsci y la izquierda socialista, en 1921, para fundar el Partido Comunista Italiano.

${ }^{35}$ Texto completo en: https://www.marxists.org/espanol/gramsci/nov1917.htm\#topp.

${ }^{36}$ Octubre 1926, Carta al Comité Central del Partido Comunista Soviético

(https://www.marxists.org/espanol/gramsci/oct1926.htm).

${ }^{37}$ http://www.feduba.org.ar/2016/07/22/cuadernos-de-la-carcel-completo-para-descargar/

${ }^{38}$ El PCE en 1978 y el PCI en 1979, abandonan la formulación estalinista "marxismo-leninismo" recuperando el primero el referente ideológico del "marxismo revolucionario" de los bolcheviques.

${ }^{39}$ La crisis y caída del bloque soviético, a finales de los años 80, hizo retroceder a las opciones comunistas, de izquierda y progresistas en todo el mundo, dio al traste con el eurocomunismo y la socialdemocracia de izquierdas, dando paso a unos años 90 dominados por el posmodernismo y el neoconservadurismo, hasta las victorias electorales de "socialismo del siglo XXI" en Venezuela y la América andina, y el movimiento social global en Occidente contra el neoliberalismo que sigue a la crisis de 2008.

${ }^{40}$ El primer nombre del Partido Comunista de Alemania fue Liga Espartaquista, bajo la dirección de Karl Liebknecht, Rosa Luxemburgo y Clara Zetkin.
} 
ya en la cúspide del Estado soviético, hace suyo el concepto aislacionista de su viejo socio ${ }^{41}$ en la lucha por el poder interno, convirtiéndose en el todopoderoso, caprichoso y abusivo Secretario General del PC soviético, justamente lo que más temía Lenin.

\section{Unión Soviética}

Caracterizamos de estalinista la etapa soviética -años 30 y 40 - que sigue a la revolución, la guerra civil, la NPE y la lucha interna dentro del partido. La desaparición durante la guerra civil ${ }^{42}$ del Partido Social-Revolucionario de Izquierda ${ }^{43}$, representante tradicional del campesinado, reduce el sistema soviético de partidos al Partido Comunista. El régimen soviético se hace con Stalin personalista, autoritario y represivo ${ }^{44}$, tanto hacia dentro como hacia fuera, en un entorno de aislamiento internacional, centralización y desarrollo económico ${ }^{45}$ que satisfará y urbanizará su base social histórica, que se movilizará exitosamente entre 1941 y 1945 contra el III Reich.

Algunos se preguntan: ¿cómo pudo durar un régimen tiránico como el soviético 70 años? Las anteojeras ideológicas les impiden percibir la historia tal como la podían ver los rusos normales ${ }^{46}$. Desde los años 30, tuvo lugar en la Unión Soviética un proceso planificado y acelerado de industrialización como nunca antes se había visto, que transformó la atrasada Rusia en una gran potencia mundial, lo que permitió -entre otras $\operatorname{cosas}^{47}$ - la victoria contra Hitler en la II Guerra Mundial. Gracias a lo anterior, el PC soviético pudo crear un colosal Estado social, comparando siempre con la Rusia heredada de los zares y la guerra, que subió el nivel de vida de los trabajadores, garantizó el empleo, la educación y la enseñanza para todos, obligando además a Occidente a hacer reformas en la misma dirección como el New Deal en los EE. UU. y el Estado de Bienestar de Keynes en Europa. Es históricamente incorrecto -además de injusto- que la II Internacional socialdemócrata se atribuya en solitario, los avances sociales en las políticas públicas en la Europa capitalista de la posguerra, sin considerar los efectos de las luchas de los trabajadores y del miedo del capitalismo -debilitado por las dos guerras mundiales- a que la Revolución Rusa se expandiera par tout.

La inclusión del Este de Europa en el bloque soviético, después de la II Guerra Mundial y las posteriores y triunfales revoluciones dirigidas por partidos comunistas en

${ }^{41}$ Bujarin fue apartado del poder por Stalin en 1929 y ejecutado, en 1938, al igual que el resto de los dirigentes del Comité Central bolchevique de 1917.

42 Algunos de los dirigentes del PSRI sobrevivientes serán también ejecutados en la Gran Purga de 1938.

${ }^{43}$ El PSRI había llegado a ser aliado de los bolcheviques en los Gobiernos del inicio de la revolución (diciembre de 1917).

${ }^{44}$ Con Stalin la Rusia soviética sigue por consiguiente la tradición absolutista de la autocracia zarista, que tendrá continuidad, una vez desaparecida la URSS, en la actual Rusia de Putin.

${ }^{45}$ El PIB de la Unión Soviética crece al 5\% anual entre 1928 y 1975, ulteriormente decae.

${ }^{46}$ Mutatis mutandis: igual que en el franquismo, la represión afectó en la URSS a una minoría reducida de la población.

${ }^{47}$ Pasó algo parecido -sin olvidar que son fenómenos históricos antagónicos en contenido, forma y finalidaden los años 60 en la España de Franco con los polos de desarrollo, el turismo y las remesas de los emigrantes que potenciaron un franquismo sociológico -mezclado con la ideología y el miedo- todavía hoy activo. 
Oriente y América Latina, mantuvieron vivo en Occidente el temor a la revolución socialista y la rivalidad capitalismo-socialismo en los años más calientes de la Guerra Fría de los años 50 y 60, cuestionada por una nueva generación a partir de 1968 desde Francia, Praga, EE. UU., México o Japón.

La otra cara de la moneda del Estado soviético de corte estalinista es la imposición de un pensamiento marxista cerrado y simplista, acuñado como "marxismo-leninismo" y basado en la obra de Stalin Los fundamentos de leninismo, publicada en $1926^{48}$, transcripción de unas conferencias que dictó en abril de 1924 en la Universidad Sverdlov ${ }^{49}$, tres meses después de la muerte de Lenin ${ }^{50}$. Marxismo de catecismo, como gusta decir Josep Fontana, que convirtió en teoría gris la creatividad siempre verde de Lenin. Potenciando una neta separación entre ideología y realidad, historia oficial e historia vivida, nomenklatura y sociedad, que explicará décadas después el derrumbe sorpresivo del socialismo llamado real como una cáscara vacía.

Lo peor, con todo, de la época estalinista es la puesta en marcha de un Gobierno tiránico alejado del pluralismo interno de la época bolchevique, en el POSDR (b) y en el PC (b), y del propio funcionamiento democrático y asambleario de los Soviets originales. Evolución autoritaria que confirma los peores temores de Lenin, Troski y otros marxistas revolucionarios de inicios del siglo XX. La culpa de Stalin por las desviaciones del proyecto original de Octubre es evidente pero relativa, salvo en lo respecta a su brutal carácter denunciado por Lenin. Stalin fue responsable en lo personal de los crímenes de Estado en los años 30 y 40, pero su ascenso y actos de poder fueron también consecuencia ${ }^{51}$ de un régimen político de entrada aislado internacionalmente, con un partido único y burocratizado, sin ninguna oposición interna o externa que hiciese de contrapeso. Gobernando, además, un país destruido por las guerras que hereda las rémoras serviles del zarismo, pretendiendo instaurar el régimen social más avanzado del mundo.

Si Lenin no hubiera muerto a los 54 años, y hubiera vivido 20 años más como Jefe del Estado soviético, con seguridad no se habría generado una dinámica de purgas tan terribles. Stalin eliminó físicamente a la mayor parte de la dirección del partido bolchevique de $1917^{52}$. Campos de concentración masivos para los disidentes, colectivización forzosa para los campesinos. Conculcación sistemática de los Derechos Humanos, que hoy serían considerados delitos de lesa humanidad imprescriptibles. Todo hay que decirlo: siguiendo el principio de realidad de Lenin y el principio de verdad de los historiadores. Hay que

\footnotetext{
${ }^{48}$ Texto completo en: https://www.marxists.org/espanol/stalin/1920s/fundam/index.htm.

${ }^{49}$ Escuela de cuadros del PC(b) fundada en 1919 que estuvo activa hasta 1937.

${ }^{50}$ Lenin difícilmente hubiera permitido, en vida, un resumen tan elemental presentado como receta universal para todos los países del mundo.

${ }^{51}$ Para entender a Stalin habría que leer de nuevo El 18 Brumario de Luis Bonaparte (1852) de Carlos Marx, donde muestra "las circunstancias y las condiciones que permitieron a un personaje mediocre... representar el papel de héroe" (https://www.marxists.org/espanol/m-e/1850s/brumaire/brum1.htm); sabiendo como acaba la historia: el protagonista mediocre francés se mantuvo en el poder hasta 1870 como Napoleón III, el último Rey de Francia.

52 ¿Hubiera podido Stalin ejecutar a Lenin? Con Lenin vivo no habría llegado a acumular en su persona el poder absoluto del Estado nacido de la revolución de 1917, la Unión Soviética no hubiera sido una sociedad democrática al estilo occidental, seguro, pero tampoco un régimen policial con millones de víctimas.
} 
hablar de las dos caras de la experiencia soviética, no sólo de la que pueda interesar a cada uno según su ideología: decir la verdad el revolucionario ${ }^{53}$.

Stalin apoyado en el culto a la personalidad, un partido uniforme artificialmente y una extensa burocracia, sobredimensiona un Estado dictatorial -cuando ya no había guerra civil ni intervención extranjera- que no quiere ni puede renunciar al miedo y a la represión para gobernar. La Unión Soviética reconstruye y amplia lo que fue geopolíticamente el Imperio euroasiático de los Zares, se hace respetar y mantiene la paz mundial mediante un peligroso equilibrio de fuerzas nucleares con el bloque capitalista. Otros países se unen durante la Guerra Fría a la órbita comunista en varios continentes, y la III Internacional lleva la influencia soviética a todos los países del mundo. Ya no hay ni acoso internacional ni "socialismo en un solo país" para mirar para otro lado sobre lo qué pasaba en Rusia, y en otros países gobernados por los comunistas (recordar la Camboya de Pol Pot) so pretexto de no favorecer al enemigo capitalista ${ }^{54}$. Menos se puede hoy en día negar u ocultar la parte oscura del pasado comunista, vivimos una afortunada globalización de los derechos humanos más o menos protegida por un nuevo derecho internacional, que reconoce justicia, verdad y reparación a todas las víctimas civiles de las dictaduras y las guerras del siglo XX, sin excepciones políticamente interesadas. La historia hay que recordarla "tal como fue" para no repetir sus inhumanos "errores".

La Gran Guerra Patria comportó un punto de inflexión en la evolución de la Unión Soviética, su alianza en 1941 con los países democráticos quiebra definitivamente su aislamiento internacional. En 1945 participa en la creación de la ONU y del Consejo de Seguridad junto con Estados Unidos, Francia, Gran Bretaña y China, todo como resultado de su papel decisivo en la derrota de Alemania ${ }^{55}$. Si Rusia tuvo en la I Guerra Mundial 2 millones de muertos, según dijimos, en la II Guerra Mundial fueron 26 millones ${ }^{56}$, contribución ingente a la lucha común de los Aliados contra las potencias del Eje BerlínRoma-Tokio. Con la Guerra Fría se quiso hacer olvidar, inútilmente, el servicio histórico que había prestó la Unión Soviética a la humanidad en los años 1941-1945.

El nuevo impulso del prestigio de la Unión Soviética que conlleva su papel en la II Guerra Mundial se refuerza en 1956 cuando Nikita Krushchov denuncia en el XX Congreso del PCUS ${ }^{57}$ como nuevo Secretario General (Stalin muere en 1953), los crímenes de Stalin apoyándose en el testamento de Lenin y los escritos de Krúpskaya, así como su modo de dirigir la URSS proporcionando referencias y datos acerca del culto a la personalidad, la exageración de su papel durante la Guerra Patria, la represión del pluralismo interno, la

\footnotetext{
${ }^{53}$ Frase atribuida en las redes a Georg Orwell, Antonio Gramsci...y Bob Marley.

${ }^{54}$ Lo mismo se puede decir, en el lado contrario, de las bombas atómicas de Nagasaki e Hiroshima so pretexto de acelerar el fin de la guerra, que contaron con la complicidad política, intelectual y académica del mundo occidental.

${ }^{55}$ Las películas norteamericanas -algunas buenas- se han pasado más de medio siglo intentando convencernos desesperadamente de que fueron los EE. UU. quienes decidieron la victoria aliada.

${ }^{56}$ Geoffrey A. HOSKING, Rulers and victims: the Russians in the Soviet Union, Harvard University Press, 2006, p. 242.

${ }^{57}$ Texto completo del discurso de Krushchov (25/2/1956) en: https://www.marxists.org/espanol/khrushchev/1956/febrero25.htm.
} 
ejecución de los viejos bolcheviques e innumerables comunistas (como la ejecución de 848 delegados del XVII Congreso del PCUS en 1934), la creación de pruebas falsas para acusar a sus adversarios personales o políticos ${ }^{58}$ o la deportación de las nacionalidades. En 1964, Krushchov fue depuesto ${ }^{59}$ y sustituido por Leonid Brézhnev al frente del Partido y del Estado. Los veinte y cinco años siguientes de la URSS serán de estalinismo sin Stalin, menos sangrientos tal vez, pero no menos dogmáticos y autoritarios, como revela la brutal represión de la Primavera de Praga en 1968. En 1982 muere Leonid Brézhnev y, en 1985, lo reemplaza Mijaíl Gorbachov que retoma el espíritu reformista de Krushchov. Será demasiado tarde, el conservadurismo y el inmovilismo de las décadas anteriores habían dejado a la Unión Soviética inerme ante el vendaval de la globalización en ciernes.

La historiografía progresista no fue ajena a estos acontecimientos perturbadores. Como la invasión soviética de Hungría el 4 de noviembre de 1956 para reprimir la Revolución del 23 de octubre ${ }^{60}$ que dio lugar al Gobierno reformista de Imre Nagy. El Grupo de Historiadores del Partido Comunista Británico que habían creado en 1952 la revista Past and Present, promotora de la escuela historiográfica marxista de mayor prestigio en el mundo occidental, se aparta en su mayoría del Partido Comunista Británico, entre ellos E. P. Thompson, Christopher Hill y Rodney Hilton, en cambio siguieron militando Eric Hobsbawm y Maurice Dobb ${ }^{61}$.

El 21 de agosto de 1968 los tanques soviéticos intervinieron de nuevo en Checoslovaquia para poner fin al "socialismo de rostro humano" de Alexander Dubcek. Recuerdo que nos confortó la crítica de la dirección del Partido Comunista de España a la intervención en Checoslovaquia poniendo fin violentamente a la Primavera de Praga, parte del movimiento histórico y generacional estudiantil del 68. El PCE ya había cuestionado meses antes el rol jugado por el Partido Comunista Francés en el Mayo francés (tachando a los estudiantes rebeldes de "pequeños burgueses"), al que nos considerábamos ligados fraternalmente. De no ser así, muchos nos hubiéramos ido del partido, en detrimento de un movimiento antifranquista universitario y obrero en auge que alcanzará en la siguiente década un punto de no retorno, haciendo posible la transición a la democracia.

Llegamos así al final de la experiencia soviética, y del siglo XX como proceso histórico, con la caída del socialismo llamado real. En 1989 se derrumba el Muro de Berlín y, en 1991, acontece el golpe de Yeltsin y la disolución de la Unión de Repúblicas Socialistas Soviéticas. El derrumbamiento del modelo soviético, que cogió por sorpresa a todos, incluidos historiadores, politólogos y científicos sociales ${ }^{62}$, sólo se comprende desde

\footnotetext{
${ }^{58}$ Por ejemplo, los procesos de Moscú 1936-1938 que llevaron a la muerte a Zinóviev, Kámenev, Bujarin, Rádek, Rykov y varios generales del glorioso Ejército Rojo.

${ }^{59}$ Krushchov falleció de muerte natural, en 1971, y fue borrado de la historia soviética hasta la desaparición de la URSS.

${ }^{60}$ El pronunciamiento antiestalinista de Krushchov en febrero de 1956 contribuyó, involuntariamente, a la Revolución húngara de octubre de 1956.

61 Harvey J. KAYE, Los historiadores marxistas británicos, Zaragoza, 1989, p. 16; Alan KNIGHT, "Mis experiencias como editor y autor en revistas históricas (con referencia particular a Past \& Present)", História, Ciências, Saúde, Manguinhos, Rio de Janeiro, v.23, n. 4, out.-dez. 2016, p. 8.

${ }^{62}$ Dejamos fuera a los Nostradamus tipo Johan Galtung.
} 
un marxismo original, ajeno a la fosilización posterior por obra del estalinismo. La crisis y el acabamiento del sistema soviético es un efecto claro del choque entre el desarrollo de las fuerzas productivas y unas relaciones de producción ${ }^{63}$ que integraban una superestructura política que desvió, después de 1945, el I+D y el presupuesto del Estado hacía la carrera armamentística y espacial, perdiendo la carrera económica con los Estados Unidos y el capitalismo occidental, al tiempo que ignoraba y/o desdeñaba las nuevas necesidades de la población $^{64}$. Todo ello en los prolegómenos de una revolución científico-técnica y de las comunicaciones sin precedentes $^{65}$, y de una globalización del mercado libre incompatible con una economía hiper nacionalizada, autárquica y centralizada como la soviética ${ }^{66}$.

La caída -sin grandes resistencias- del "socialismo real" en el Este de Europa está provocada en una importante movilización de masas en algunos países, como Alemania o Polonia -donde la iniciativa es del movimiento obrero- a diferencia de Rusia, donde el poder soviético simplemente se desfondó, en medio estaría la situación de Rumanía, donde en 1989 un levantamiento armado -como en la Hungría de 1956- terminó con el ajusticiamiento de Nicolae Ceaucescu.

El retorno impensado del capitalismo quiebra el dogma marxista-leninista de los cinco estadios (esclavismo, feudalismo / capitalismo / socialismo / comunismo) que consideraba irremediable el paso de una etapa a otra sin prever la transición inversa del socialismo al capitalismo. El mentís histórico y objetivo del catecismo estalinista, trufado de estructuralismo, que para el mejor marxismo occidental ya estaba desprestigiado en los años 70, hizo retroceder así mismo la confianza en el marxismo en su conjunto, y, en general, en todas las ideologías y filosofías basadas en la noción ilustrada del progreso, dando alas al posmodernismo, el neoconservadurismo y el neoliberalismo, a su vez en crisis -justicia histórica- en este nuevo siglo abocado a nuevas luchas y objetivos históricos ${ }^{67}$.

El capitalismo que retornó en Rusia, y a otros países del Este de Europa, semejaba más del siglo XIX que del siglo XXI. Manifiestamente subdesarrollado, mafioso inclusive, ha dado lugar a una gran desigualdad social. En la Rusia postsoviética empeoraron las condiciones de vida y de trabajo de la gente, se multiplicó por diez el número de pobres, bajó de manera notoria la esperanza de vida de la población. Perdieron de golpe los rusos el Estado social construido a partir de la Revolución de Octubre, pese a las desviaciones: el

\footnotetext{
${ }^{63}$ La caída de la URSS fue, de todos modos, un colapso político más que un colapso económico, si se pudiera separar en el "modo de producción soviético" la estructura de la superestructura...

${ }^{64}$ La dimensión autocrática, policial y burocrática del Estado soviético lo mantuvo durante décadas separado de la gente corriente, salvo durante el paréntesis de la Guerra Patria que amenazó las vidas de todos, dirigentes y dirigidos.

${ }^{65}$ La URSS se desarrolló con la segunda revolución industrial del carbón y la energía nuclear, pero no estaba preparada para la tercera revolución industrial digital, de las comunicaciones y la energía renovable.

${ }^{66}$ En la misma tesitura el Partido Comunista de China se convirtió al capitalismo de Estado y consiguió ser gracias al librecambismo- la segunda potencia económica del mundo, manteniendo el partido único marxistaleninista y el absolutismo del Estado y reprimiendo, en consecuencia, cualquier protesta social o política interna.

${ }^{67}$ Carlos BARROS, "Los fines de la historia en el siglo XXI”, III Foro Internacional Rusia e Iberoamérica en el mundo globalizante: historia y perspectivas, Universidad Estatal de San Petersburgo, Rusia, 2-4 de octubre de 2017 (http://cbarros.com/fines-de-la-historia-en-el-siglo-xxi/).
} 
derecho al empleo, la educación y la sanidad; la aportación soviética al desarrollo de las universidades y las ciencias. No nos extraña que en un sondeo reciente, el $53 \%$ de la población rusa manifestara una visión positiva de Lenin (y de otros líderes soviéticos como Dzherzhinski y Stalin) ${ }^{68}$. Tampoco que a un político postsoviético tan avispado como Putin (antiguo funcionario de la KGB) se le atribuya en las redes la frase siguiente: "quien no extraña a la Unión Soviética no tiene corazón, quien la quiere de vuelta no tiene cerebro". Hay que decir que no tiene demasiada autoridad Putin para decirlo (en el caso probable de que sea suya), siendo conservador, neoliberal y nacionalista gran-ruso. El actual Presidente de la Federación Rusa es un agradecido reconocedor del estatus de gran potencia alcanzado por la Unión Soviética con Stalin ${ }^{69}$. Le resulta fácil así beneficiarse electoralmente de la nostalgia soviética entre los rusos de hoy, manteniendo para ello la momia de Lenin en la Plaza Roja para que los ciudadanos exsoviéticos -y los turistas- puedan visitarlo: si levantara la cabeza...

\section{Un siglo después}

¿Cómo se ve desde el siglo XXI el acontecimiento y el proceso histórico abierto por la Revolución de Octubre? Estamos en una época radicalmente diferente. Lenin escribió en 1916 El imperialismo, fase superior del capitalismo, donde los grandes Estados capitalistas diputaban entre ellos por la dominación del mundo. Hoy, la globalización viene a ser como la "fase superior" de la "fase superior" del capitalismo, donde los viejos Estados-nación tratan todo lo más de sobrevivir frente a los poderes fácticos globales de las finanzas y multinacionales a quienes sirven, por un lado, y a las redes sociales que los critican o ignoran, por el otro. Obviamente, Lenin no lo pudo prever: la etapa imperialista se basó en el dominio absoluto del Estado y la globalización neoliberal necesita la subordinación de los Estados a los mercados.

En cierto sentido estamos ahora peor que hace un siglo. Piketty demostró en su tesis doctoral $^{70}$ como a partir de los años 70 ha ido creciendo la desigualdad económica y social, superando con el cambio de siglo a la existente antes de la crisis de 1929, con el agravante de que presentemente la población mundial y la tarta a repartir son mucho mayores. A lo que hay que sumar la inesperada crisis de 2008 que ha durado una década, y otras que pueden venir después, ante la falta de control con la que actúan los mercados financieros, la inmensa e impagable deuda, el agotamiento de las energías fósiles o la creciente economía sumergida $^{71}$.

\footnotetext{
${ }^{68} 100$ años de la Revolución Rusa, El País, Madrid, 7/11/2017 (https://elpais.com/internacional/2017/11/01/actualidad/1509538218_218371.html).

69 Tocante a la adoración de Rusia como una gran potencia mundial, Stalin se inspiraba en los zares, las monarquías absolutas y los imperios históricos; para nada en el marxismo, contrario desde Marx hasta Gramsci, pasando por Lenin, a un Estado Leviatán antitético de un Estado socialista que prepararía las condiciones para una sociedad sin clases, igualitaria y autogestionada.

${ }^{70}$ Thomas PIKETTY, El Capital en el siglo XXI, México, 2014.

${ }^{71}$ Ver los diferentes escenarios en: http://cbarros.com/fines-de-la-historia-en-el-siglo-Xxi/.
} 
El capitalismo sigue provocando sus propias crisis como en los tiempos de Marx, que ahora una globalización económica agrava por su descomunal capacidad de difusión y amplificación de lo malo y de lo bueno. Pero no estamos al final de la historia, si no en un nuevo comienzo. En el nuevo siglo se viene a manifestado también globalmente una nueva generación indignada y vitalmente anticapitalista, no tanto por razones ideológicas, al estilo del siglo XX, como por su propia experiencia social de generación académicamente formada -más que nunca- en los países desarrollados, consciente de no tiene un lugar claro en el futuro que el capitalismo global está construyendo para el siglo XXI.

En este contexto surgen voces que hablan, cien años después, de la renovada vigencia de la Revolución Rusa de Lenin y los bolcheviques, pese a su evolución autoritaria y la radical mutación de las condiciones históricas, por lo de ningún modo vale copiar miméticamente. En el presente, las opciones marxistas, o relacionadas con el marxismo, activas y políticamente ganadoras siguen en la práctica caminos bien diferentes que los que siguió el bolchevismo para conseguir parecido objetivo de transformación social.

Con el siglo vivimos ahora un auge de movimientos sociales, con escaso protagonismo del movimiento obrero tradicional, que tantos éxitos obtuvo en el siglo XX, ahora debilitado cualitativa, numérica y estructuralmente. Los nuevos movimientos sociales tienen una base social diferente y diversa, jóvenes precarios o desempleados, muchos de ellos universitarios, minorías de edad, género ${ }^{72}$ o etnia, que tienden a movilizarse de manera global. Nuevo movimiento social global que, en un plazo de dos décadas también ha hecho estremecer el mundo. En 1999 encentó en Seattle el movimiento antiglobalización o altermundista. En 2011, espoleado por la crisis de 2008 y sus consecuencias, se alzó el movimiento de los indignados ${ }^{73}$ que atravesó varios continentes hasta 2016 (Nuit debout en Francia), también en México (YoSoy132, Ayotzinapa, la respuesta de los jóvenes al terremoto de 2017 en CDMX...). A falta de soluciones para esta globalización desmadrada es probable que en la tercera década del siglo XXI se produzca una tercera ola de los indignados de la generación millennials ${ }^{74}$, la única hoy por hoy que podemos comparar con la generación -asimismo intercontinental- de Mayo del 68, cuyo 50 aniversario celebramos en 2018.

Al mismo tiempo, surge en América del Sur, de 1998 en adelante, la experiencia asimismo inesperada del "socialismo del siglo XXI"75, actualmente en fase de repliegue ${ }^{76}$,

\footnotetext{
${ }^{72}$ El próximo 8 marzo de 2018 tendrá lugar en 177 países la primera huelga feminista global de la historia.

73 Carlos BARROS, "Historia Inmediata: de Chiapas a los indignados", conferencia inaugural del XXVII Congreso Internacional Historia Regional / VII Encuentro de Historiadores de Sinaloa. Culiacán, 8 de diciembre de 2011 (http://www.youtube.com/watch?v=bHqkczWoBwE); "Historia global de los indignados (2011-2014), conferencia en la Escuela Nacional de Antropología e Historia. México DF, 29 de setiembre de 2014 (https://youtu.be/_nWXygiVR1Q).

74 Millennials: jóvenes que se hacen históricamente adultos con el nuevo milenio; otras denominaciones temporales, superficiales y mediáticas como generación $\mathrm{X}, \mathrm{Y}$ o Z de poco sirven para una seria Historia Inmediata.

${ }^{75}$ Carlos BARROS, "Historia inmediata: marxismo, democracia y socialismo del siglo XXI (problemas y debates)", Fuentes. Revista de la Biblioteca y Archivo Histórico de la Asamblea Legislativa Plurinacional,

La Paz (Bollivia), año 10, vol. 5, $\mathrm{n}^{\mathrm{o}}$ 13, abril 2011, pp. 36-44 (http://cbarros.com/spanish/articulos/mentalidades/hi_socialismo.htm).
} 
de interés en el tema conmemorativo que nos ocupa puesto que conlleva cierta "vuelta al marxismo" -que muchos consideraban en bancarrota total después de la Caída del Muro ${ }^{77}$ como guía de la acción política. Lo más llamativo de la nueva izquierda bolivariana es, además de iniciar la construcción de un Estado social en Venezuela, Ecuador y Bolivia, el acceso al poder a través de elecciones, la aceptación más o menos entusiasta del pluralismo partidario y de la democracia como forma de gobierno, a diferencia de lo que fue el modelo soviético del siglo XX. Tiene un especial valor por tratarse de países con escasa historia democrática, incluso de tradición golpista.

El precedente histórico más cercano es el sueño pacífico de Salvador Allende y el "socialismo en libertad" eurocomunista también de los años 70, y el más lejano es la valoración que, en 1895, el propio Engels hizo del sufragio universal en Alemania -donde el SPD había conseguido ya dos millones de votos- como un "instrumento de emancipación", celebrando como "los partidos del orden, como ellos se llaman, se van a pique con la legalidad creada por ellos mismos" ${ }^{78}$. Vía revolucionaria pacífica y democrática de toma del poder que se vio frustrada, en el siglo XX, en Alemania y Europa Occidental, por las guerras imperialistas, el nazifascismo, la Guerra Fría, además de los logros del Estado de Bienestar gracias a las luchas y los "treinta gloriosos" años de desarrollo económico entre 1945 y 1973.

Otra novedad del "socialismo del siglo XXI" es la asunción de la cohabitación de la empresa pública con la economía de mercado, como una NEP permanente. Es evidente que, en la era global, una economía no puede sobrevivir al margen del mercado, autárquicamente, otra cosa es dejar que los mercados sin patria, especulativos y bursátiles, sigan mandando más que nuestros representantes elegidos. De ahí que el proteccionismo en el siglo XXI sea cosa de reaccionarios como Trump o los partidarios del Brexit. Para transformar el mundo, aquí y ahora, es principio de realidad aceptar -críticamente- la interdependencia económica global ${ }^{79}$, que pone de actualidad la dimensión necesariamente mundial de la revolución socialista, según defendieron los fundadores del marxismo. Lo mismo valdría decir en este momento de cualquier otra iniciativa política o social

\footnotetext{
${ }^{76}$ En democracia, la alternancia es inevitable, en caso de perder el Gobierno en unas elecciones ante la derecha, el consenso popular acumulado les posibilitará regresar, salvo que quemen los barcos dinamitando desde el poder la democracia electoral.

${ }^{77}$ Mientras el capitalismo siga vivo, y engendre crisis y desigualdades, el marxismo no desaparecerá, crecerá con sus fracasos y menguará con sus éxitos, y viceversa: la capacidad de adaptación de ambos e interconectados contendientes a los cambios será decisiva.

78 Introducción a Carlos MARX, La lucha de clases en Francia de 1848 a 1850 (https://www.marxists.org/espanol/m-e/1850s/francia/francia1.htm).

${ }^{79}$ Por ejemplo, la dependencia de Venezuela del petróleo cuyas subidas y bajadas afectan tanto a la economía y las políticas sociales; Rodrigo Londoño "Timochenko", líder del partido FARC, criticaba así recientemente (28/1/2018) la experiencia chavista: "no se puede vivir únicamente de la renta, hay que desarrollar la industria", "las políticas sociales tienen que tener como base el desarrollo económico y no depender exclusivamente de los subsidios" (http://www.semana.com/nacion/articulo/entrevista-rodrigo-londonotimochenko-como-candidato-de-la-farc/554946).
} 
encaminada, en el presente siglo, a controlar democráticamente la globalización económica $^{80}$.

Volviendo a 1917, ¿qué puede significar la Revolución de Octubre en el siglo XXI? Un referente histórico, historiográfico e identitario. Decía León Trotsky, en su "Historia de la Revolución Rusa", redactada en 1932, que "aun suponiendo que ... el régimen soviético fuera derrocado temporalmente... sería un ejemplo para todo el desarrollo futuro de la humanidad"81. Sí, pero no. Cien años después, la Revolución Rusa ha caído en el olvido para la gran mayoría de la gente, incluidos los nuevos trabajadores industriales: principio de realidad. Recientemente Pablo Iglesias, en una mesa redonda conmemorativa en Madrid del centenario de la Revolución de Octubre mostró su admiración por el genio de Lenin y la Revolución Rusa, demostró -decía- que se puede convertir "lo imposible en real" y que "la política puede ganar a la historia" " 82 . En fin, el "sí se puede" que justamente dio nombre al partido Podemos ${ }^{83}$, surgido del $15 \mathrm{M}$ del cual Iglesias es secretario general. Se trata, en realidad de una posición individual como profesor de Ciencia Política versado en la historia del siglo XX. Como movimiento social el 15-M tuvo, no obstante, más del anarquismo que del leninismo: sin dirigentes, asambleario, tanto o más más espontáneo que los soviets rusos de 1905 y 1917, o los consejos obreros de Turín de 1920. Seguidamente el partido Podemos fue otra cosa, ahí entran otros ingredientes de tipo intelectual y político, así y todo, se trata de algo nuevo, las decisiones fundamentales, internas y externas, las toman por Internet el casi medio millón de inscritos, y tienen como meta presentarse a las elecciones y ganar el Gobierno a fin de alcanzar una democracia real, plena y social. Para nada, pues, un partido leninista de vanguardia como el PSDR (b) o el PCR (b), organizado para la clandestinidad y la insurrección armada.

La Revolución Rusa en el siglo XXI no da votos debe ser tarea de historiadores y profesores de historia hacer que no se olvide tan grande evento, y sus efectos, que marcaron de manera indeleble la historia del siglo XX, sin lo cual mal se comprendería el presente convulso que vivimos. La óptica correcta como historiadores es tratar de comprender los hechos en su contexto ${ }^{84}$, sin dejar de tener en cuenta los valores del presente: de forma que comprender no signifique justificar barbaridades, por razones de honestidad y pedagogía. Y menos aún se deben proyectar hacia atrás sin más nuestras ideologías actuales ${ }^{85}$, las

\footnotetext{
${ }^{80}$ Ver el apartado sobre Gobierno Mundial democrático en http://cbarros.com/fines-de-la-historia-en-el-sigloxxi/.

${ }^{81}$ Alan WOODS, “La Revolución Rusa: El Significado de Octubre”, 2017 (https://www.marxist.com/larevolucion-rusa-el-significado-de-octubre.htm).

82 "Iglesias elogia la capacidad de Lenin de convertir lo imposible en real", El País, 10/10/2017 (https://politica.elpais.com/politica/2017/07/26/actualidad/1501059673_006149.html).

${ }^{83}$ Carlos BARROS, "Podemos desde la historia" (2015)

(https://www.academia.edu/18142282/Podemos_desde_la_historia).

${ }^{84}$ Verbigracia Julián CASANOVA, La venganza de los siervos. Rusia, 1917, Madrid, 2017.

85 Dos ejemplos, Santos Julia cuando adopta el punto de los mencheviques en 1917 ("Centenario de la Revolución Rusa. ¡Qué importan los hechos!”, El País 30/1/2017

https://elpais.com/cultura/2017/01/27/babelia/1485532030_075027.html), o Richard Pipes (ex-miembro del Comité de Seguridad Nacional de Ronald Reagan) cuando se posiciona en favor de los blancos en La revolución rusa (1992); posiciones ambas derrotadas de manera contundente por la historia: el Partido
} 
verdades históricas que contengan nuestras legítimas interpretaciones se resienten de ello. En cualquier caso, como en otros hechos históricos relevantes del pasado siglo, la polémica está servida, dentro y fuera de la historia académica. La demostración de que la Revolución Rusa de 1917 sigue historiográficamente viva es el debate que ha generado en su centenario. La posición historiográfica más útil es, por tanto, la que tome en consideración el contexto de las diferentes épocas del proceso soviético, así como los datos y fuentes que se han ido descubriendo, empezando por las investigaciones innovadoras de E. H. Carr y la historiografía social anglosajona y francesa de los años 60 y $70^{86}$, sin coartar en ningún momento el debate entre historiadores y no historiadores.

El único camino desde una historiografía de valores profesionales y morales es analizar la Revolución Rusa partiendo del punto de vista de sus protagonistas, favorables y contrarios, junto con los datos generales sobre 1917, su gestación, prolongado y discutido impacto, de manera crítica y autocrítica, por mucho que hechos y conclusiones molesten a la ideología que pueda o pudo tener cada uno de nosotros. Cuestión aparte son los militantes o exmilitantes donde, a diferencia de los historiadores, cuenta más la posición subjetiva, por lo que se llega a menudo a negar o minusvalorar los datos probados que estorban a la propia identidad ideológica, en especial la parte criminal del estalinismo, algo que no puede hacer el historiador de oficio.

Decíamos que la valoración presente de lo que fue y significó la Revolución de Octubre puede ser histórica, historiográfica e identitaria, yendo de lo más objetivo a lo más subjetivo. Consideramos legítima que alguien quiera preservar incólume su ideología como parte de su biografía e identidad personal, otra cosa es avalar como proyecto político colectivo, implícita o explícitamente, el relativismo moral o el negacionismo respecto de la deriva autoritaria y represiva del estalinismo, inaceptable en nuestro tiempo. Somos parte de una generación que evolucionamos - "sólo la vida dirá la última palabra” decía Leninporque no traicionamos las enseñanzas medulares y originarias de la Revolución Rusa: emancipación social y democracia auténtica.

Comunista de Rusia sigue siendo la fuerza principal de la izquierda, a diferencia de otros países del Este de Europa donde lo son partidos socialdemócratas, por otro lado, el Putin nacionalista actual admirador del pasado soviético no desde luego equiparable a la ultraderecha de la guerra civil de Pipes.

86 Pepe GUTIÉRREZ-ÁLVAREZ, "El Siglo soviético de Moshe Lewin, un breviario insuperable”, 2017 (http://kaosenlared.net/siglo-sovietico-moshe-lewin-breviario-insuperable/). 